\title{
Policy forums: Why do they exist and what are they used for?
}

\author{
Manuel Fischer ${ }^{1,2} \cdot$ Philip Leifeld ${ }^{1,2,3}$
}

Published online: 11 July 2015

(C) Springer Science+Business Media New York 2015

\begin{abstract}
Policy forums are issue-based intermediary organizations where diverse types of political and societal actors repeatedly interact. Policy forums are important elements of modern governance systems as they allow actors to learn, negotiate, or build trust. They can vary in composition, size, membership logic, and other distinct features. This article lays the foundation of a theory of policy forums based on three interrelated elements: First, it discusses conditions for the formation of a forum and describes the logic of these organizations as one of an asymmetric multipartite exchange. Second, it enumerates the potential set of goals and motivations of participating actors that are fed into this exchange. Third, it proposes eight different dimensions on which policy forums differ and which affect the exchange mechanisms among actors. We claim that empirical work on policy forums should systematically take these elements into account and propose elements of a research agenda.
\end{abstract}

Keywords Policy forum - Governance $\cdot$ Exchange theory $\cdot$ Intermediary organization

\section{Introduction}

Since the decline of hierarchical decision making and the emergence of networks as a "new form of [political] governance" some 30 years ago (Powell 1990; Börzel 1998; Hajer 2003), manifold types of policy forums have emerged in the political landscape. Against

Manuel Fischer

manuel.fischer@eawag.ch

1 Department of Environmental Social Sciences, Swiss Federal Institute of Acquatic Science and Technology (Eawag), Überlandstrasse 133, 8600 Dübendorf, Switzerland

2 Institute of Political Science, University of Berne, Fabrikstrasse 8, 3012 Bern, Switzerland

3 Zukunftskolleg, University of Konstanz, Universitätsstrasse 10, 78457 Konstanz, Germany 
the increasing complexity and fragmentation of public policy making, policy forums are supposed to facilitate the coordination among authorities, interest groups, or scientific experts. By providing a space for interaction, policy forums aim for horizontal, rather than vertical, integration (Bogason and Musso 2006). This is especially important for dealing with policy issues characterized by scientific complexity and uncertainty (Gollier and Treich 2003; Lubell 2013) or spanning multiple traditional policy subsystems (Hoberg and Morawski 2008; Jones and Jenkins-Smith 2009). Prime examples are policy forums on topics like water, energy, public health issues, or sustainable development.

Subforms of policy forums have been described in various branches of literature, namely on collaborative, adaptive or polycentric governance and collective action theory, regulatory governance, deliberation, corporatism, epistemic communities, venue shopping, the ecology of games, science and technology studies, policy advice, transaction cost politics, and resource dependence theory. Besides "policy forum" (Kinzig and Starrett 2003), the literature uses various overlapping concepts like "boundary organization" (Guston 2001), "bridging organization" (Hahn et al. 2006), "intermediary organization” (Braun 1993), "policy committee" (Leifeld and Schneider 2012), "collaborative institution” (Lubell 2004), "game" (Lubell et al. 2010), "advisory group" (Agrawala 1999; Parkins 2002), "advisory committee" (Vasseur et al. 1997), "working group" (Klijn et al. 1995), "multi-organizational boards" (Klijn and Skelcher 2007), "partnerships" (Selsky and Parker 2005), and "roundtable" (Jamal and Getz 1999; Turcotte and Pasquero 2001). ${ }^{1}$ It is currently unclear how these different concepts relate to each other. The goal of this article is not to provide a systematic literature review, but to lay the foundation of an integrated theory of policy forums by synthesizing these hitherto mostly separate but complementary branches of literature.

More specifically, we ask how we can understand the existence and functioning of policy forums. Given that forums are created in a bottom-up manner by any type of actor, and actors are basically free to choose whether or not to participate in a forum, we rely on a rationalchoice institutionalist framework. This theoretical focus allows to understand actors' participation in policy forums and the specific characteristics of forums as the outcome of individual considerations of actors with regard to their resources and needs. Our argument is based on three interrelated elements: First, we discuss the formation of policy forums based on the logic of an asymmetric multipartite exchange of resources among actors. Second, we enumerate the potential set of goals and motivations of participating actors that are fed into this exchange within the forum. Third, we propose several dimensions on which policy forums may differ and which relate to the exchange mechanisms among actors.

Research on policy forums is highly relevant for political science and public administration, given the contrasting opinions about their role for democracy (Sörensen and Torfing 2005; Klijn and Skelcher 2007). On the one hand, policy forums have been accused of undermining democratic legitimacy and being ineffective tools of governance. Two main arguments have been put forth. First, policy makers have been elected to craft policies, and bureaucrats are paid well to formulate and implement them. If decisions are actually prepared in committees composed of members without an official mandate, this is a waste of resources but also a potential backdoor for advocacy. This "boardization" lacks transparency and accountability (Bogason and Musso 2006; Klijn and Skelcher 2007; Wilks 2007) and leads to "deparliamentarization," a "democratic deficit," or a "control gap" (Krick 2006). Second, deliberation in policy forums can lead to either of two extreme outcomes: expertocracy or technocracy, where experts dominate and bias policy making

1 These concepts are all interchangeably called "policy forums" in the remainder of this article because we would like to provide a unified framework for their analysis. 
toward technical solutions (Busch 2009), and the use of policy forums by politicians or bureaucrats in order to legitimize their policies through scientific credibility ("policy-based evidence-making," Busch 2009). On the other hand, the literature also discusses positive aspects of policy forums. It notably emphasizes civil society participation and the establishment of a "public sphere" as well as balanced decisions due to extensive deliberation (Rowe and Frewer 2000; Parkins 2002; Feldman and Khademian 2007; Klijn and Skelcher 2007). In addition to this increased input legitimacy, a higher "quality" of decisions can be expected due to the contribution of expert and stakeholder knowledge that is otherwise inaccessible to decision makers.

The remainder of this article is organized as follows: The next section delineates the scope of policy forums and distinguishes them from similar types of organizations. The "Multipartite exchange and resource dependence" section suggests a framework for the analysis of policy forums based on rational-choice institutionalism and multipartite resource exchanges between participants. The next two sections analyze the phenomenon from two opposite sides: The "Goals of actors participating in policy forums" section disentangles the various goals of the participants, and the "Characteristics of forums" section proposes a set of characteristics according to which policy forums can differ. The concluding section sums up the dimensions in which policy forums can be analyzed and suggests key items for a future research agenda on policy forums.

\section{Delineating policy forums}

As compared to other collaborative structures, policy forums have a number of distinct features: They have organizational boundaries between the forum and the outside issue network, give rise to repeated interaction, include diverse members without serving a single interest, and deal with political or societal issues.

First, policy forums are all characterized by some form of organization beyond a mere network of actors dealing with an issue. There are clearly defined boundaries including members and regular participants whose membership is publicly disclaimed. The result is a special flavor of network governance, which is neither based on informal ties between actors only (as in the idea of "issue networks," see Heclo 1978), nor close to "policy communities" with strict boundaries and preferential access to decision makers are imperative (Rhodes and Marsh 1992; van Waarden 1992). Policy forums can rather be understood as organized, stable arrangements situated in the larger network of actors, where resources are exchanged among members. Interactions between members of a policy forum and the outside world are common, yet the organizational boundary between members and non-members prevents non-members from taking part in the interactions inside the forum.

Second, policy forums are not merely one-shot conferences, but exert some stability over time, potentially on a permanent basis. For example, a policy forum on freshwater quality or on demographic challenges serves as a knowledge exchange or negotiation venue for political, scientific, and corporate members dealing with these issues. To be effective and satisfy actors' goals, they interact on a regular basis. While one-shot conferences are possible, they do not belong to the distinct type of policy forum we are addressing here. They are rather events sponsored by organizations such as forums, and they do not act on their own vis-à-vis the outside world. 
Third, policy forums are not advocacy organizations for a specific interest. Policy forums can pursue broad interests that are acceptable to everyone, like "increasing the quality of decisions" or "discussing issues related to water," but they do not act as partisan or advocacy organizations toward the outside world. This alleged neutrality distinguishes policy forums from similar types of organizations with more partial goal orientations, like recurring conferences of partisan actors, advocacy groups, or think tanks. Quite a number of non-governmental organizations carry the label "policy forum" although they have obvious policy goals and advocacy purposes. ${ }^{2}$ These organizations do not belong to the group of organizations we call policy forums. Rather, policy forums have diverse types of members, even from opposing camps, and can integrate politicians, local stakeholders, organized interests, and scientific experts alike (Head 2008). This also distinguishes them from organizations like economic peak associations or intergovernmental conferences, which usually have multiple but not diverse members.

Fourth, policy forums deal with policy-related issues. This usually excludes repeated strategic meetings between firms. However, while a focus on policy-relevant issues is mandatory, government actors are not required to be the initiators of a forum; policy forums can well be established by firms or advocacy groups who invite other actors to participate. Moreover, policy forums do not necessarily focus on decision making; they can as well deal with other stages of the policy cycle, such as problem recognition (usually with a stronger expert component), implementation (usually with the involvement of practitioners), or policy formulation (often with a stronger involvement of organized interests). While policy forums center around specific political or societal issues, they are not part of the official decision-making institutions of the government (neither bureaucracy nor parliament). This excludes parliaments or cabinets from the definition.

Finally, the definition given above implies several delineations from other concepts: Policy forums are a subset of policy venues_all policy forums may be called "venues," but there are venues that do not qualify as forums, such as intergovernmental conferences (because they do not have diverse members) or open consultations (because they do not have clear organizational boundaries). Similarly, all policy forums can be called "institutions" because they have an organizational boundary, a time horizon that exceeds a single event, and they are based on explicit or implicit rules. There are, however, institutions such as a state constitution that do not have (diverse) members or organizational boundaries.

Policy forums may have different types of internal rules. What they have in common is that their members coordinate exchanges of resources, such as knowledge, information, compliance, or ideas. The remainder of this article serves to interpret forums as instances of multipartite exchanges that are initiated as a function of the actors' demand and supply of different types of resources.

\section{Multipartite exchange and resource dependence}

According to our definition, policy forums are founded in a bottom-up manner by any type of actors, and other actors are free to choose whether or not to participate in a forum. We therefore rely on actor-centered approaches such as rational-choice institutionalism (Hall and Taylor 1996) and the institutional collective action framework (Feiock 2013) to

\footnotetext{
${ }^{2}$ An example is the Global Policy Forum with its advocacy for accountability and citizen participation.
} 
understand why policy forums exist. ${ }^{3}$ These approaches posit that political actors are generally goal-oriented and (boundedly) rational. In order to participate in a forum, actors must recognize a relation between forum participation and a likely outcome, i.e., a certain probability that they can achieve their goals (Ansell and Gash 2008; Feiock and Scholz 2010). The expected gains from forum participation must be higher than the opportunity costs of not pursuing a competing activity plus the transaction costs implied by participation in the forum (Feiock 2013). Transaction costs are the time and resources to be invested in getting access to the forum, preparing for the meetings, and spending time in forum meetings. Additional forum-specific transaction costs are barriers that prevent actors from reaching coordinated decisions and take the form of information costs, negotiation costs, or enforcement costs (Koontz and Moore Johnson 2004; Feiock 2013).

\section{Symmetric versus asymmetric games and resource exchange}

Policy forums provide collective goods to participants-often policy solutions in the sense of Ostrom (1990). However, we argue that collective goods are merely one type of outcome that can motivate actors to participate in a forum. Additionally, forum participation can also result in individual benefits for actors. To elaborate on both options, we distinguish between symmetric and asymmetric exchange.

The typical example for a symmetric exchange producing collective goods is the one of fisheries management, which assumes that local users exchange concessions in their fishing behavior. They agree on equal or complementary usage patterns to achieve the common good of avoiding overfishing. All actors have the same demand-avoiding overfishing-and the same concessions to offer-a reduction in fishing or subordination to general rules like time schedules or spatial usage restrictions. As policy forums have diverse types of members, a symmetric exchange situation is, however, most often unlikely. In the majority of situations where policy forums operate, asymmetric exchange is more likely. An exchange situation is asymmetric if participants have different types of resources or if resources are distributed unequally among actors. The consequence of asymmetric exchange is that some actors might gain more than others from an exchange of resources within a forum.

Resource dependence theory predicts that organizations need to exchange resources with others (Pfeffer and Salancik 1978; Thomson and Perry 2006) to achieve their goals. Whether actors participate in a policy forum depends on (1) what resources they require and whether others can satisfy their demand, and (2) what resources they have to offer and whether their offer satisfies other actors' demands (Thomson and Perry 2006). For example, regular meetings of policy committees in corporatist arrangements can be understood as a tripartite exchange between trade unions, employers' associations, and governmental actors (Molina and Rhodes 2002): Trade unions offer willingness to comply with arrangements to employers' associations and receive concessions concerning wages and labor conditions from them, and government receives social peace from both parties in

\footnotetext{
${ }^{3}$ It may be possible to understand policy forums and participation of actors therein based on other theoretical premises. For example, sociological institutionalism would posit that all forums take a similar form because of prevalent norms in the wider political system ("institutional isomorphism," see DiMaggio and Powell 1983) or that actors participate in forums due to mutually shared norms in a policy sector. Similarly, governance approaches would emphasize that forums per se come about as a functional requirement of horizontal coordination between political actors (Powell 1990). However, while insights from these theoretical strands may be valuable for explaining the existence of a phenomenon like policy forums per se, only an individual rational-choice institutionalist account permits us to discriminate between the different characteristics of policy forums and the actors' related individual resources and needs.
} 
exchange for allowing self-governance and providing its service as a facilitator and enforcer (Ostrom 1990).

Another example of asymmetric exchange is a forum designed to foster exchange between scientists/experts, politicians, companies, journalists, and celebrities, like the World Economic Forum (Graz 2003). In this case, different resources are exchanged: Scientists lend their expertise and credibility to the forum and gain visibility and reputation in return; politicians offer legitimacy as an "official" series of events and access to decision-making institutions, and they gain visibility, new contacts, policy advice, and the ability to send signals to other politicians; companies sponsor the forum with their money for a better image as well as contacts to politicians and thus access to decision makers; celebrities help to transport other participants' messages to a wider audience and are able to polish their own charity image by being included in the forum; and journalists exchange their time and a medium for transporting the other participants' messages for news stories they can sell. One can expect some actors to gain relatively more than other actors due to the asymmetry of resources that are exchanged, but each participant still expects to earn more returns than he or she has invested, otherwise the actor would not participate in the first place. Therefore, asymmetric exchange is not about collective goods, but rather about private goods for each participant (cf. Knight 1992).

\section{Multipartite coordination and interdependent goals}

In an asymmetric exchange situation, actors must coordinate to reach their goals, and one way to organize this exchange are policy forums. Governmental actors, for example, participate in corporatist negotiation forums because failure to govern effectively would lead to their replacement. Trade unions participate because their legitimacy depends on successful bargaining for better wages (Bouwen 2004).

Still, mutual exchange could be organized in dyadic one-shot events or more endurable dyadic network relationships. We argue that the requirement of multipartite, asymmetric exchange is the reason why policy forums are founded instead of simply pursuing dyadic exchanges. Without the asymmetric component, forums would reduce to the subtype of collective action groups where all members offer the same concessions and get a public good. Without the multipartite component, forums would reduce to dyadic exchanges. However, exchanges are costly, and organizations always choose the organizational type of exchange that minimizes these costs while guaranteeing the same outcome. Therefore, actors will only prefer forums if multipartite exchange is necessary.

Multipartite exchange is defined as an exchange among more than two parties where the exchange cannot be disaggregated in dyadic relationships. For example, an exchange with four parties where $A$ gives $a_{1}$ to $C, C$ sends $c_{1}$ to $A, B$ sends $b_{1}$ to $D, D$ returns $d_{1}$ to $B$, and $A$ trades $a_{2}$ with $D$ and gets $d_{1}$ in return can be easily disaggregated into three mutual exchanges $A C=\left\{a_{1}, c_{1}\right\}, B D=\left\{b_{1}, d_{1}\right\}$, and $A D=\left\{a_{2}, d_{1}\right\}$ in order to save the transaction costs of the forum with four members in excess of the dyadic exchanges with two members each. In contrast, a true multipartite exchange is an exchange where such a dyadic disaggregation is not feasible, for example when $A$ sends $a_{1}$ to $B, B$ sends $b_{1}$ to $C$, and $C$ sends $c_{1}$ to $A$. In some cases, some but not all exchanges can be disaggregated, for example where $A$ sends $a_{1}$ to $B$ in return for $b_{1}$, and $C$ grants $c_{1}$ both to $A$ and $B$ in return for the joint outcome $\left\{a_{1}, b_{1}\right\}$ of the exchange between $A$ and $B$. This corresponds to the tripartite exchange between trade unions, employers' associations, and the state where the state gets compliance, social peace, and low-cost governance from the mutual exchange between the two peak associations and grants self-governance to these parties. Based on 
the goals actors seek to achieve by participating, one can derive distinct types of policy forums.

However, multipartite exchange — or formation of a forum — does not occur when actors play a zero-sum game. As forums consist of repeated interactions, actors who lose more than they gain on average across rounds will leave the forum. In a zero-sum game, this is by definition the case for at least one member of the forum (unless no actor ever realizes net gains, in which case formation of the forum would still be useless for any of the actors).

\section{Goals of actors participating in policy forums}

In the previous sections, we provided explanations of how individual incentives for participation in policy forums lead to a collective rationality of forum existence. However, the goals and expected benefits from the exchanges within a forum may differ between participants. Eight complementary goals of participants can be distinguished (see also Koontz and Moore Johnson 2004). Some of these goals might be more important for organizations from the public, private, scientific, or societal domains. Yet, independently of these actor categories, there are two basic types of participants who enjoy different benefits from forum participation: regular participants on the one hand and forum founders on the other. The distinction is important, as the latter have additional incentives like setting the agenda or determining who may participate.

\section{Solving policy problems}

Actors might participate in or set up a policy forum because they want to contribute to finding substantive solutions to policy problems. In this perspective, actors want to contribute to finding a solution that successfully tackles the problem at hand, reduces conflict, and is mutually beneficial to all actors concerned with the issue. They adopt a problem-solving attitude, i.e., a state of mind in which they focus on long-term goals such as the creation of value, better projects, and a general increase in welfare (Scharpf 1988, 2006), independent of individual short-term policy success. This is emphasized by the literature on collaborative institutions and policy making (Leach et al. 2002; Thomson and Perry 2006; Lubell et al. 2010), adaptive (Crona and Parker 2012) or collaborative governance (Ansell and Gash 2008), collective action institutions (Lubell et al. 2002), or deliberative policy making (Choi and Robertson 2014). Independently of whether all forum participants can offer the same resources to others, actors contribute to the problem-solving process with their specific resources such as expertise or moderation of their individual preferences. This is true for simple participants as well as for forum founders, even though the latter might get extra credit for the solution of a policy problem and therefore be ready to invest more resources such as time or leadership.

\section{Asserting individual policy positions}

On the contrary, actors may participate in policy forums because they want to lobby for their own preferred solution and achieve an individual benefit independent of a good overall solution (Krueger 1974; Leach et al. 2002; Lubell et al. 2010). As argued above, policy forums with asymmetric interdependencies favor the participation of actors who pursue private rather than public goods because their preferred outcomes are not necessarily beneficial to the other participants. Forums in which actors mainly participate to defend their own, 
pre-defined preferences instead of contributing to an overall acceptable solution are also called "adversarial institutions" (as opposed to collaborative institutions; Lubell et al. 2002; Lubell 2003, 2004). Actors are willing to invest their resources as long as they can exchange them for a forum output close to their individually preferred solution.

\section{Legitimization}

Legitimization can mainly be pursued by forum founders. Actors might initiate policy forums with scientists and stakeholders in order to legitimize their political goals rather than to achieve real counseling or knowledge transfer. Experts are then merely part of the game because they are needed to justify policy making of the government or policy proposals of interest groups (Weingart 2006), especially regarding highly conflictual issues (Lundin and Öberg 2014). Busch (2009) calls this process "policy-based evidence-making." In this perspective, experts do not deliver objective truth, but rather "serviceable truth," which is "a state of knowledge that satisfies tests of scientific acceptability and supports reasoned decision making" (Jasanoff 1990; Agrawala 1999). This function of policy advice is emphasized in the early literature on the advocacy coalition framework (Sabatier 1987), as well as on advisory committees, scientific policy advice, evidencebased policy making, and science and technology studies (von Beyme 1988; Jasanoff 1990; Agrawala 1999; Lövbrand 2007).

The exchange in this specific situation mostly concerns experts (scientists, local stakeholders, etc.) and forum founders. Whereas the latter gain legitimization, they need to be able to offer something to the actors they use to legitimize their issue. In exchange of legitimization of a policy position, scientists might get visibility and reputation (see below), and stakeholders might benefit from agenda setting or a favorable policy solution (see below and above).

\section{Visibility and reputation}

Actors may participate in forums in return for increased visibility and reputation. In this case, forum participation confirms that the actor is regarded as competent and important in the respective issue area. Scientists, for example, might get recognition from peers if they are selected to report on a given issue (The LSE GV314 Group 2013). An important reason why actors engage or support a deliberative forum is the potential to improve their public image or to avoid a negative image due to non-participation (Hendriks 2006).

On top, founders or leaders of forums gain additional credits for setting up a policy forum that aims at solving a given problem. Getting public visibility and an image as entrepreneur and active problem solver can be beneficial for actors vis-à-vis other actors and the public. For example, political parties and governmental actors can benefit from such an image, but also firms sometimes initiate forums which are instrumental for improving their public image. In terms of exchange, actors who want to benefit from forum participation in order to get visibility and reputation must be able to offer another resource, such as expertise or moderation of their policy positions.

\section{Agenda setting}

Forums can not only grant visibility to actors, but also to issues. Actors can use policy forums for agenda setting (Baumgartner and Jones 1993; Wolfe et al. 2013), i.e., to put an 
issue or problem on the political or public agenda. Bringing an issue to public attention on behalf of a whole forum-including different kinds of actors-increases the pressure to discuss the issue and find a solution for it.

What is more, forums are sometimes founded in order to increase the visibility of an issue and hence as an agenda-setting instrument. Setting up a policy forum which deals with a given issue is one way to show other actors and the public that the issue is worth to be dealt with. It is also an opportunity to frame a problem in a way that corresponds to the founder's political goals. Yet, in terms of exchange, the actors interested in setting an issue on the agenda or framing it in a specific way by discussing the issue in a forum need to be able to offer something to other forum participants. In the case of forum founders, this will most often be visibility.

\section{Shifting the decision-making venue}

A similar phenomenon as with agenda setting has been observed with regard to venue shopping. This proposition was advanced by Baumgartner and Jones (1991), who argue that "policy losers" shift the policy venues until they have enough supporters for their preferred policy. Also, if a government agency prefers a certain policy outcome and is able to anticipate that veto players will prevent this outcome from being realized, then it may try to declare the policy as an issue that has to be discussed by experts from various fields and that, accordingly, has to be dealt with in a newly established policy forum rather than within the political sphere. In order to increase their chances of success, actors thus select the forum that maximizes their chances of transforming their preferences into policy (Pralle 2003; Lubell et al. 2010). Based on a negative experience with a given forum, actors might decide to abandon the forum if participating in alternative forums is expected to enhance the odds of successful goal attainment (Pralle 2003).

\section{Reduction in uncertainty and learning}

Actors dealing with a given problem usually want to learn about it (Leach et al. 2002; Berardo et al. 2013). Policy forums allow for the exchange of technical know-how, knowledge about policy options and their potential consequences (Kinzig and Starrett 2003), as well as the preferences of other actors (Leach et al. 2002; Leifeld and Schneider 2012). In particular, deliberative forums are likely to foster social learning among actors (Hoppe 2011; Choi and Robertson 2014) or actors' learning about citizens' preferences (Hendriks 2005, 2006). Bridging or boundary organizations bring together policy makers and experts and aim at establishing a knowledge exchange between groups of actors with different types of knowledge (Cash et al. 2006; Crona and Parker 2012). Learning can also take place within corporatist arrangements (Öberg 2002).

Particularly, governmental actors responsible for making policy decisions set up forums in order to consult stakeholders and learn about their preferences in order to make the "right" decision (Nagel 2006). A public manager thus has an interest in bringing together relevant actors in order to enhance the design as well as the implementation of policies (Feldman and Khademian 2007) via mutual exchange of expertise before a decision is made. 


\section{Networking and trust building}

By participating in forums, actors can establish network contacts with other actors interested in the same issue (Leach et al. 2002; Lubell et al. 2002; Feiock and Scholz 2010; Lubell et al. 2010). Forums serve as institutional opportunity structures for actors to develop contacts, cooperation, and social capital (Leifeld and Schneider 2012), and thereby to reduce their behavioral uncertainty (Berardo et al. 2013) and create trust (Berardo 2009; Lubell 2007).

Corporatist arrangements (Öberg 2002), boundary organizations (Hahn et al. 2006), and deliberative forums (Hendriks 2006) all create trust and a common understanding of given issues among participating actors, which facilitates a long-term dialogue (Feldman and Khademian 2007; Crona and Parker 2012). For example, bargaining between trade unions and employers' associations relies on the experience of employers' associations that their concessions indeed lead to cooperative behavior of the trade unions' constituency.

Beside trust-which concerns any type of actor participating in the same forum-policy forums may have a connective capacity when they link actors from otherwise distinct organizational fields or societal spheres. The literature on boundary organizations suggests that actors from science and politics use policy forums as an opportunity to collaborate because they would otherwise hardly get in touch with each other (Hahn et al. 2006; Crona and Parker 2012).

\section{Characteristics of forums}

The potential benefits of exchanges in forums depend not only on actors' goals, but also on the characteristics of forums (Feiock 2013), which vary on at least eight dimensions (see also Koontz and Moore Johnson 2004). For each of them, we discuss how the specific characteristics affect exchange processes among actors.

\section{Composition}

First, forums can differ with respect to their internal composition. Potential forum participants are either individuals, such as experts, or-more likely-representatives of collective actors such as state agencies, interest groups, political parties, private firms, local stakeholders, or scientific organizations (Hardy and Koontz 2009). Depending on the purpose of the forum, different types of actors are included. For example, if the goal of a policy forum is to elaborate policy implementation plans, the inclusion of local actors can be important for figuring out whether proposed actions work in a particular context. Including the political domain can be important for finding out what actions are likely to be adopted and funded or how to achieve political awareness of an issue. The scientific or technical domain is important for informing actors on what actions will solve particular problems (Feldman and Khademian 2007), especially with respect to highly complex and uncertain policy issues (McAllister et al. 2013).

There are several ideal types with respect to composition: One ideal type involving mainly stakeholders and users is a local forum of collaborative governance. The literature on collaborative institutions emphasizes the importance of inclusiveness with respect to stakeholders who are affected (Lubell 2003; Ansell and Gash 2008). Deliberation studies emphasize the importance of citizen participation for the legitimacy and the quality of 
decisions (Habermas et al. 1964; Landre and Knuth 1993; Vasseur et al. 1997; Rowe and Frewer 2000; Parkins 2002). Still, the risk with strong citizen participation is that it may complicate the determination of public preferences and create ambiguity as to how much weight these inputs from citizens should be given (Steelman and Ascher 1997).

A second ideal type including mostly scientific experts and political actors directly responsible for an issue are advisory groups, boundary organizations, or bridging organizations (Cash et al. 2006; Gulbrandsen 2011; Crona and Parker 2012). Boundary or bridging organizations can also include local actors, if their goal is to play an intermediary role and foster knowledge exchange between different arenas, levels, and scales (Cash et al. 2006). Advisory groups usually include experts in order to solve specific problems and representatives of the agencies seeking expert advice or justification.

Finally, corporatist arrangements as a third ideal type focus on important interest groups. These forums are usually not inclusive, but the centralization of actors on both sides (i.e., unions and business) is even a pre-condition for being recognized as negotiation partners.

Generally, including different types of actors is important for the forum to be able to address given issues. However, as different types of actors have different logics of functioning, forums with highly diverse sets of actors might have a harder time to interact and exchange resources, or they need a facilitating leader to do so (Provan and Kenis 2008; Krause and Douglas 2012).

\section{Size}

In general, forums are established when every participant's welfare is increased as compared to non-establishment of the forum. For example, if there are eight users of a common pool resource, and six users have established a policy forum, the choice of whether a seventh user is invited to the forum depends on whether they can prevent the resource from being depleted without the seventh user or if the user is necessary to make a decision. In common pool resource settings, having all users on board usually leads to a higher chance of solving the dilemma (Ostrom 1990). In other settings, like corporatist forums, increasing fragmentation on each side would lead to less efficient outcomes. Therefore, actors are organized in peak associations which take part in the negotiations.

In general, there is an implicit tension between group size and the capacity of selfgovernance of policy forums (Olson 1965; Feiock and Scholz 2010). As the number of actors participating in a forum increases, the number of potential actor relations grows exponentially. This increases transaction costs: The sheer number of actor relations and the fact that face-to-face interaction is rarer with a larger number of actors both complicate self-governance of the forum (Provan and Kenis 2008). With a high number of forum participants, a central broker or leader can facilitate interactions between actors (Provan and Kenis 2008, see also next subsection). Further, the ideal size of a forum depends on other conditions, such as the diversity of participants, their goal consensus, or the expertise needed in a forum (Provan and Kenis 2008; Krause and Douglas 2012).

What is more, the size of the policy forum influences the function it can adopt: Whereas a broad group can develop networks and share information effectively, narrow groups can take positions on issues and act in ways broader groups cannot (Koontz and Moore Johnson 2004). 


\section{Organization and leadership}

Forums differ with respect to their internal organization, which influences their capacity to foster exchange and to satisfy participants' goals (Pralle 2003). At one extreme point, actors can simply present their preferences, negotiate, and try to find a solution without any internal hierarchy, rules of organizations, or specific roles of actors. In this informal setting, power between actors can only be balanced when sufficient time is allocated to the deliberative process (Choi and Robertson 2014). At the other extreme point, forums can be guided by strict procedural rules, formal institutions, and official leaders that guide the interactions of participants.

Between these two ideal-typical extremes, there are forums in which facilitators, leaders, or moderators are responsible for the design of the internal decision-making process (Feldman and Khademian 2007). The presence of a facilitating leader simplifies the collaborative process (Vasseur et al. 1997; Folke et al. 2005; Ansell and Gash 2008), not least because a leader might absorb transaction costs by providing critical resources (Emerson et al. 2012). For instance, the role of state actors is a key to facilitating and organizing corporatist negotiations between labor and business (Thompson 2008; Woldendorp and Keman 2010). A public manager can create opportunities for participation, provide information, facilitate deliberation (Feldman and Khademian 2007), or speed up consensus formation (Vasseur et al. 1997). Last but not least, third parties can act as enforcers of agreements if they have the necessary formal authority and can thus additionally facilitate consensus formation (Ostrom 1990).

A facilitator or leader is a forum member who enables other forum members to exchange resources where such an interaction would not be feasible without the facilitator. In some cases, this is part of the multipartite exchange; facilitating discussion or negotiation is a competence that is traded for other resources, such as policy goal attainment, visibility, or legitimization. Just like "network managers" (Klijn et al. 1995), forum members can possess various types of resources that make them facilitators: "soft" skills like a vision or leadership skills, relational assets like advantageous network positions (e.g., "brokerage" positions), or credible formal authority that can be exerted via economic sanctions or exclusion of others from the forum (Klijn et al. 1995).

\section{Decision-making mode}

Related to the previous point, it is of crucial importance to assess whether the forum aims at achieving a consensus solution, whether it allows for multiple voices, or whether a final decision is made by a majority decision. Most of the literature on collaborative governance (Ansell and Gash 2008), collaborative institutions (Lubell 2003), or collaborative policy making (Leach et al. 2002) emphasizes that decision making in forums should be consensus-oriented. A certain degree of formal rules, for example a unanimity rule for decisions, can be useful as it prevents outside power relations from playing out in the forum as well (Choi and Robertson 2014). Such a rule can also increase the procedural fairness as perceived by actors (Berardo et al. 2013). However, if conflict is high and/or some participants defend extreme positions, the need for consensus might impede successful resource exchange and actual decision making (Choi and Robertson 2014).

\section{Degree of transparency}

Forums can be transparent and open to public scrutiny or, alternatively, the activities of forums can take place "behind closed doors." Transparency is often assumed to be a key 
characteristic for successful collaborative governance in forums (Leach et al. 2002; Ansell and Gash 2008), and is one of the most prominent conditions with respect to the quality of deliberation (Rowe and Frewer 2000; Thompson 2008; Bächtiger and Hangartner 2010).

The advantage of transparency is that actors not participating in the forum as well as the general public are aware of who is taking which decision for what reasons in the forum. This increases the credibility and legitimacy of the forum and its outcomes (Hendriks 2006). Further, speakers under public observation are more likely to treat their opponents in a respectful way and take their arguments seriously (Thompson 2008).

In some cases, however, the absence of a public sphere can even lead to better outcomes from the perspective of forum members. When deliberating and negotiating behind closed doors without public scrutiny, actors are under less pressure to follow their constituents' demands and cannot lose their face if they have to change their positions or admit the complexity of the problem (Thompson 2008; Bächtiger and Hangartner 2010). Advisory committees, for example, are rather working behind closed doors (Leach et al. 2002).

What is more, increasing media coverage fosters the tension between the "logic of influence," which is compromise-oriented and prevalent among the negotiators of corporatist organizations, and the "logic of membership," which stresses fidelity to the objectives of their respective reference groups (Streeck and Schmitter 1985; Häusermann et al. 2004).

Potential advantages of excluding the public (from the perspective of forum members, not democratic accountability) are realized when non-members would otherwise interfere with the exchange realized in the forum. For example, if a state agency and representatives of private firms discuss regulatory policy instruments, the firms might want to avoid interference by trade unions who are not part of the forum, and the politicians who take part in the deliberations might want to avoid public visibility because this would inhibit policy-related learning as voters might punish them for inconsistent views over time in a debate. On the other hand, forum members may sometimes have an incentive for "venue shifting" by going public. For example, when opponents try to assert unpopular policies (the threat of) going public is a bargaining resource.

Advisory forums where politicians or agencies seek justification for their policies can only serve a legitimizing function if there is a public audience (Weingart 2006). Moreover, if a forum is made transparent, it is less suspicious in terms of lobbyism because lobbying usually takes place behind closed doors. Conversely, the initiator of a forum may want to avoid transparency in order to pursue lobbying activities, to avoid the criticism of merely serving a legitimization function, or simply to increase the quality of decisions by avoiding distractions.

\section{Compliance}

Decisions made in policy forums can be binding and enforceable, or the compliance of actors with forum outputs is voluntary. In the logic of venue shopping, the utility of participating in a forum with binding decisions versus non-binding deliberation can differ (Damro 2006). Contrary to adversarial institutions that rely on coercive penalties for implementation, collaborative institutions rely on voluntary compliance (Lubell 2003). However, the users of a resource can make binding contracts and designate an enforcer to overcome their collective action situation (Ostrom 1990).

If forum outputs are non-binding, actors risk less if they participate in the forum-they can simply choose not to comply with a decision they do not agree with. However, repeated interaction in the forum often effectively promotes compliance in the absence of 
enforcement rules. Furthermore, if an output is non-binding, actors might be less motivated to participate and invest resources in the forum exchange.

\section{Specificity of the issue and time horizon}

Policy forums can serve to resolve a specific problem, or they can deal with a broader field (Feiock 2013). In the first case, the forum is set up in order to solve a well-defined problem and exists only until the problem has been solved. The literature on polycentric, adaptive, or collaborative governance (Lubell 2003; Scholz and Stiftel 2005; Ansell and Gash 2008) emphasizes that actors organize forums in a bottom-up way to specifically deal with a given problem.

The second type is rather a kind of permanent standing group with a broader issue scope and a longer time horizon (Leach et al. 2002). When the scope is broad and there are multiple relations between actors, trust developed between actors dealing with a given issue facilitates negotiations on other issues involving the same set of actors (Feiock 2013). As a classic example, corporatism is defined by long-term partnerships between state, business, and labor that deal with several different issues in the domain of social, industrial, and education policy (Siaroff 1999). The long-term character of the arrangements creates trust among actors (Öberg 2002). Also, expert groups and advisory groups (Busch 2009) are often used as an "extension" of the administrative apparatus and can thus have a long-term horizon.

The issue specificity of a forum influences the expected benefits of actors' forum participation, and their participation depends on whether they rather have narrow and short-term interests or long-term and broader interests. The literature on venue shopping emphasizes the importance of whether narrow or broad issues are decided upon in a forum (Damro 2006). Inclusiveness increases the level of perceived satisfaction; people who want to include a wide range of interests tend to believe some common ground can be found among them (Lubell et al. 2010).

\section{Exclusiveness}

Finally, a policy forum can be the exclusive venue where a given problem is tackled, or it can be one among several forums where actors deal with the same problem. With respect to the second option, the ecology of games literature (Long 1958; Dutton 1995; Lubell et al. 2010; Smaldino and Lubell 2011; Dutton et al. 2012) posits that actors deliberately choose to participate in several parallel forums according to their specific knowledge, interests, or strategic behavior. However, participation in multiple forums might be collectively dysfunctional (Smaldino and Lubell 2011) as actors have limited capacities and resources to invest in decision making. The literature on venue shopping (Pralle 2003; Damro 2006; Nagel 2006) points to the fact that multiple forums dealing with the same substantial problem allow actors to select the forum they favor in terms of their chances for success, which might be detrimental to successful overall decision making. Similarly, deliberative forums are often simply one among several distinct types of participation (Hoppe 2011). Therefore, forum exclusiveness with respect to the problem that is dealt with is described as one of the most important characteristics of successful institutional design in collaborative governance (Ansell and Gash 2008). If actors can expect successful resource exchange in an exclusive forum, this should increase their motivation to participate. 


\section{Conclusions}

"Policy forum" is an umbrella term for issue-based organizations where diverse types of political and societal actors repeatedly engage in multipartite exchange. The goal of this article is to lay the foundation of an integrated theory of policy forums. At its core, the existence, design, and outcomes of a forum follow from the need for multipartite exchanges between actors. We consciously adopted a rational-choice institutionalist approach to understand why forums exist and why actors would participate therein. Alternatively, a sociological institutionalist approach would put emphasis on different explanatory factors such as generally accepted norms and values as the main explanatory factors for forum existence and participation.

The elaboration of our conceptual model of policy forums is based on a broad set of literature. The model consists of a list of eight goals actors strive to achieve as a result of the multipartite exchange in policy forums, on the one hand, and a list of eight characteristics of policy forums which influence these exchanges, on the other. The theoretical discussion of this model is an important contribution to the understanding of the functioning of policy forums. However, we were able to only scratch at the surface of actors' goals and forum characteristics, and many related implications were not developed in this paper. As such, the related future research agenda is broad and diverse.

First, a logical next step is to apply this model to empirical cases in the form of qualitative case studies or with a comparative research design. We do not know à priori how a given policy forum works without examining the exchanges in detail. We suggest that researchers who deal with "boundary organizations," "bridging organizations," "policy forums," "policy committees," "collaborative institutions," "games," "advisory groups," "advisory committees," "working groups," "partnerships," "roundtables," “intermediary institutions," and similar concepts first describe the exchanges taking place within the organization and the properties of the organization by partitioning the forum and its members into the categories proposed here. Empirically, some elements, such as forum composition or size, are easy to assess as the information is most often available from archival sources. Most other characteristics, however, require either in-depth study of the respective policy sector (exclusiveness) or outputs (compliance, specificity), or interviews with or surveys among forum participants, founders, or managers. By studying the dimensions discussed in this article, the exchanges taking place inside forums can be inferred.

Whereas many empirically observable forums combine different characteristics discussed in this article, specific types of policy forums are probably more prevalent than others in some policy sectors or polities. For example, policy forums might be especially important in the environmental sector, where coordination between different sectors is crucial for the optimal use of scarce resources and where the interaction between scientific knowledge and policy making is crucial in the face of wicked problems such as climate change or the degradation of biodiversity. We also expect important differences across countries. There is evidence for different "civic epistemologies" and cultures of coordination among authorities, stakeholders, and scientists across countries (Jasanoff 1987, 2011; Lentsch and Weingart 2011). For example, corporatist committees (Molina and Rhodes 2002) and comitology (Joerges and Neyer 1997; Gornitzka and Sverdrup 2008) can be found mainly in Europe, while collaborative institutions rather exist in polities with less regulation by the state. Assessing these differences and deducing some ideal types of policy forums based on the characteristics we discussed in this paper are important tasks for future research in this domain. 
Research questions that need further scholarly attention with respect to policy forums abound: For example, we should study the role of a policy forum in a polity, as it might replace more formal institutions of the political system or exist as parallel venues and thereby increase system redundancy and stability (Landau 1969; Klijn and Skelcher 2007). What is more, there are exchange or dependency relations between different types of forums, not least in terms of joint members. Assessing such an ecology of forums and their relations is crucial for understanding the political system as a whole (see also Sörensen and Torfing 2005; Edelenbos et al. 2010; Lubell et al. 2010; Lubell 2013).

The research agenda on policy forums also includes important normative questions. As briefly touched upon in the introduction, we have to ask whether policy forums are beneficial or detrimental for democracy. From a democracy-theoretical perspective, are they preferable because civil society is involved in policy making, or are they objectionable because a diffusion of responsibility takes place and elected politicians can no longer be held accountable for policy outcomes? The view presented in this article is agnostic of these normative judgments; however, we have provided the right tools to evaluate forums and classify them. This should facilitate a comparison of policy forums across polities and time in order to eventually reach a conclusion in normative terms.

Finally, research on policy forums is not only crucial in a scholarly perspective and for the academic understanding of the political system, but research on this topic also facilitates evaluations of specific policy forums from a practitioner's perspective. If a forum was designed to achieve specific goals, but it does not perform well, the framework described in this paper can help to sort out what institutional aspects of the forum must be changed in order to achieve the multipartite exchanges the forum was designed for in the first place. However, we do not formulate general recommendations to policy makers on how to design useful and good forums because the latter depends on the goals actors want to pursue by founding or participating in a forum in the first place.

\section{References}

Agrawala, S. (1999). Early science-policy interactions in climate change: Lessons from the advisory group on greenhouse gases. Global Environmental Change, 9(2), 157-169.

Ansell, C., \& Gash, A. (2008). Collaborative governance in theory and practice. Journal of Public Administration Research and Theory, 18(4), 543-571.

Bächtiger, A., \& Hangartner, D. (2010). When deliberative theory meets empirical political science: Theoretical and methodological challenges in political deliberation. Political Studies, 58, 609-629.

Baumgartner, F. R., \& Jones, B. D. (1991). Agenda dynamics and policy subsystems. The Journal of Politics, 53(4), 1044-1074.

Baumgartner, F. R., \& Jones, B. D. (1993). Agendas and instability in American politics. Chicago: The University of Chicago Press.

Berardo, R. (2009). Generalized trust in multi-organizational policy arenas: Studying its emergence from a network perspective. Political Research Quarterly, 62(1), 178-189.

Berardo, R., Lubell, M., \& Scholz, J. T. (2013). Who participates in an ecology of games and why? A comparison across weakly and strongly institutionalized policy-making systems. Paper presented at 2013 MPSA meeting, Chicago.

Bogason, P., \& Musso, J. A. (2006). The democratic prospects of network governance. The American Review of Public Administration, 36(1), 3-18.

Börzel, T. A. (1998). Organizing Babylon-On the different conceptions of policy networks. Public Administration, 76(2), 253-273.

Bouwen, P. (2004). Exchanging access goods for access: A comparative study of business lobbying in the European Union institutions. European Journal of Political Research, 43(3), 337-369. 
Braun, D. (1993). Who governs intermediary agencies? Principal-agent relations in research policy-making. Journal of Public Policy, 13(2), 135-162.

Busch, A. (2009). Politikwissenschaft und Politikberatung: Reflektionen anlässlich der aktuellen Krise. Zeitschrift für Politikberatung, 2(3), 467-484.

Cash, D. W., Adger, W. N., Berkes, F., Garden, P., Lebel, L., Olsson, P., et al. (2006). Scale and cross-scale dynamics: Governance and information in a multilevel world. Ecology and Society, 11(2), 8-19.

Choi, T., \& Robertson, P. J. (2014). Deliberation and decision in collaborative governance: A simulation of approaches to mitigate power imbalance. Journal of Public Administration Research and Theory, 24(2), 495-518.

Crona, B. I., \& Parker, J. N. (2012). Learning in support of governance: Theories, methods, and a framework to assess how bridging organizations contribute to adaptive resource governance. Ecology and Society, $17(1), 32-50$.

Damro, C. (2006). The new trade politics and EU competition policy: Shopping for convergence and cooperation. Journal of European Public Policy, 13(6), 867-886.

DiMaggio, P. J., \& Powell, W. W. (1983). The iron cage revisited: Isomorphism and collective rationality in organizational fields. American Sociological Review, 48, 147-160.

Dutton, W. H. (1995). The ecology of games and its enemies. Communication Theory, 5(4), 379-392.

Dutton, W., Schneider, V., \& Vedel, T. (2012). Ecologies of games shaping large technical systems: Cases from telecommunications to the internet (pp. 49-68). Berlin/Heidelberg: Springer.

Edelenbos, J., Schie, N., \& Gerrits, L. (2010). Organizing interfaces between government institutions and interactive governance. Policy Sciences, 43(1), 73-94.

Emerson, K., Nabatchi, T., \& Balogh, S. (2012). An integrative framework for collaborative governance. Journal of Public Administration Research and Theory, 22, 1-29.

Feiock, R. C. (2013). The institutional collective action framework. Policy Studies Journal, 41(3), 397-425.

Feiock, R. C., \& Scholz, J. T. (2010). Self-organizing governance of institutional collective action dilemmas (pp. 3-26). Cambridge/New York: Cambridge University Press.

Feldman, M. S., \& Khademian, A. M. (2007). The role of the public manager in inclusion: Creating communities of participation. Governance, 20(2), 305-324.

Folke, C., Hahn, T., Olsson, P., \& Norberg, J. (2005). Adaptive governance of social-ecological systems. Annual Review of Environmental Resources, 30, 441-473.

Gollier, C., \& Treich, N. (2003). Decision-making under scientific uncertainty: The economics of the precautionary principle. Journal of Risk and Uncertainty, 27(1), 77-103.

Gornitzka, A., \& Sverdrup, U. (2008). Who consults? The configuration of expert groups in the European Union. West European Politics, 31(4), 725-750.

Graz, J.-C. (2003). How powerful are transnational elite clubs? The social myth of the World Economic Forum. New Political Economy, 8(3), 321-340.

Gulbrandsen, M. (2011). Research institutes as hybrid organizations: Central challenges to their legitimacy. Policy Sciences, 44, 215-230.

Guston, D. H. (2001). Boundary organizations in environmental policy and science: An introduction. Science, Technology, and Human Values, 26(4), 399-408.

Habermas, J., Lennox, S., \& Lennox, F. (1964). The public sphere: An encyclopedia article. In S. E. Bonner \& D. Kellner (Eds.), Critical theory and society: A reader. New York: Routledge.

Hahn, T., Olsson, P., Folke, C., \& Johansson, K. (2006). Trust-building, knowledge generation and organizational innovations: The role of a bridging organization for adaptive comanagement of a wetland landscape around Kristianstad, Sweden. Human Ecology, 34(4), 573-592.

Hajer, M. (2003). Policy without polity? Policy analysis and the institutional void. Policy Sciences, 36, $175-195$.

Hall, P. A., \& Taylor, R. C. (1996). Political science and the three new institutionalisms. Political Studies, 44, 936-957.

Hardy, S. D., \& Koontz, T. M. (2009). Rules for collaboration: Institutional analysis of group membership and levels of action in watershed partnerships. The Policy Studies Journal, 37, 3.

Häusermann, S., Mach, A., \& Papadopoulos, Y. (2004). From corporatism to partisan politics: Social policy making under strain in Switzerland. Swiss Political Science Review, 10(2), 33-59.

Head, B. W. (2008). Assessing network-based collaborations: Effectiveness for whom? Public Management Review, 10(6), 733-749.

Heclo, H. (1978). Issue networks and the executive establishment. In A. King (Ed.), The new American political system (pp. 87-124). Washington: American Enterprise Institute.

Hendriks, C. M. (2005). Participatory storylines and their influence on deliberative forums. Policy Sciences, $38,1-20$. 
Hendriks, C. M. (2006). When the forum meets interest politics: Strategic uses of public deliberation. Politics and Society, 34(4), 571-602.

Hoberg, G., \& Morawski, E. (2008). Policy change through sector intersection: Forest and aboriginal policy in Clayoquot Sound. Canadian Public Administration, 40(3), 387-414.

Hoppe, R. (2011). Institutional constraints and practical problems in deliberative and participatory policy making. Policy and Politics, 39(2), 163-168.

Jamal, T., \& Getz, D. (1999). Community roundtables for tourism-related conflicts: The dialectics of consensus and process structures. Journal of Sustainable Tourism, 7(3-4), 290-313.

Jasanoff, S. S. (1987). Contested boundaries in policy-relevant science. Social Studies of Science, 17(2), 195-230.

Jasanoff, S. (1990). The fifth branch: Science advisors as policymakers. Cambridge: Harvard University Press.

Jasanoff, S. (2011). Designs on nature: Science and democracy in Europe and the United States. Princeton: Princeton University Press.

Joerges, C., \& Neyer, J. (1997). From intergovernmental bargaining to deliberative political processes: The constitutionalisation of comitology. European Law Journal, 3(3), 273-299.

Jones, M. D., \& Jenkins-Smith, H. C. (2009). Trans-subsystem dynamics: Policy topography, mass opinion, and policy change. The Policy Studies Journal, 37(1), 37-58.

Kinzig, A., \& Starrett, D. (2003). Coping with uncertainty: A call for a new science-policy forum. AMBIO: A Journal of the Human Environment, 32(5), 330-335.

Klijn, E.-H., Koppenjan, J., \& Termeer, K. (1995). Managing networks in the public sector: A theoretical study of management strategies in policy networks. Public Administration, 73(3), 437-454.

Klijn, E.-H., \& Skelcher, C. (2007). Democracy and governance networks: Compatible or not? Public Administration, 85(3), 587-608.

Knight, J. (1992). Institutions and social conflict. Cambridge: Cambridge University Press.

Koontz, T. M., \& Moore Johnson, E. (2004). One size does not fit all: Matching breadth of stakeholder participation to watershed groups accomplishments. Policy Sciences, 37, 185-204.

Krause, G. A., \& Douglas, J. W. (2012). Organizational structure and the optimal design of policymaking panels: Evidence from consensus group commissions' revenue forecasts in the American states. American Journal of Political Science, 57(1), 135-149.

Krick, E. (2006). Politikberatung durch Expertengremien: Legitimation und Funktion der 'Hartz'- und der 'Rürup'-Kommission. Arbeitspapier 2/2006, University of Osnabrück, Social Science Faculty, Osnabrück.

Krueger, A. O. (1974). The political economy of the rent-seeking society. The American Economic Review, 64(3), 291-303.

Landau, M. (1969). Redundancy, rationality, and the problem of duplication and overlap. Public Administration Review, 29(4), 346-358.

Landre, B. K., \& Knuth, B. A. (1993). Success of citizen advisory committees in consensus-based water resources planning in the Great Lakes basin. Society and Natural Resources, 6(3), 229-257.

Leach, W. D., Pelkey, N. W., \& Sabatier, P. A. (2002). Stakeholder partnerships as collaborative policymaking: Evaluation criteria applied to watershed management in California and Washington. Journal of Policy Analysis and Management, 21(4), 645-670.

Leifeld, P., \& Schneider, V. (2012). Information exchange in policy networks. American Journal of Political Science, 53(3), 731-744.

Lentsch, J., \& Weingart, P. (2011). The politics of scientific advice: Institutional design for quality assurance. Cambridge: Cambridge University Press.

Long, N. E. (1958). The local community as an ecology of games. American Journal of Sociology, 64, $251-261$.

Lövbrand, E. (2007). Pure science or policy involvement? Ambiguous boundary-work for Swedish carbon cycle science. Environmental Science and Policy, 10(1), 39-47.

Lubell, M. (2003). Collaborative institutions, belief-systems, and perceived policy effectiveness. Political Research Quarterly, 56, 309-323.

Lubell, M. (2004). Collaborative environmental institutions: All talk and no action? Journal of Policy Analysis and Management, 23(3), 549-573.

Lubell, M. (2007). Familiarity breeds trust: Collective action in a policy domain. Journal of Politics, 69, 237-250.

Lubell, M. (2013). Governing institutional complexity: The ecology of games framework. The Policy Studies Journal, 41(3), 537-559.

Lubell, M., Henry, A. D., \& McCoy, M. (2010). Collaborative institutions in an ecology of games. American Journal of Political Science, 54(2), 287-300. 
Lubell, M., Schneider, M., Scholz, J. T., \& Mete, M. (2002). Watershed partnerships and the emergence of collective action institutions. American Journal of Political Science, 46(1), 148-163.

Lundin, M., \& Öberg, P. (2014). Expert knowledge use and deliberation in local policy making. Policy Sciences, 47, 25-49.

McAllister, R. R. J., McCrea, R., \& Lubell, M. N. (2013). Policy networks, stakeholder interactions and climate adaptation in the region of South East Queensland, Australia. Regional Environmental Change, 14(2), 527-539.

Molina, O., \& Rhodes, M. (2002). Corporatism: The past, present, and future of a concept. Annual Review of Political Science, 5, 305-331.

Nagel, P. (2006). Policy games and venue-shopping: Working the stakeholder interface to broker policy change in rehabilitation services. Australian Journal of Public Administration, 65(4), 3-16.

Öberg, P. (2002). Does administrative corporatism promote trust and deliberation? Governance, 15(4), 455-475.

Olson, M. (1965). The logic of collective action: Public goods and the theory of groups. Cambridge: Harvard University Press.

Ostrom, E. (1990). Governing the commons: The evolution of institutions for collective action. Cambridge: Cambridge University Press.

Parkins, J. (2002). Forest management and advisory groups in Alberta: An empirical critique of an emergent public sphere. The Canadian Journal of Sociology, 27(2), 163-184.

Pfeffer, J., \& Salancik, G. R. (1978). The external control of organizations: A resource dependence perspective. New York: Harper \& Row.

Powell, W. W. (1990). Neither market nor hierarchy: Network forms of organization. Research in Organizational Behavior, 12, 295-336.

Pralle, S. B. (2003). Venue shopping, political strategy, and policy change: The internationalization of Canadian forest advocacy. Journal of Public Policy, 23(3), 233-260.

Provan, K. G., \& Kenis, P. (2008). Modes of network governance: Structure, management, and effectiveness. Journal of Public Administration Research and Theory, 18, 229-252.

Rhodes, R. A. W., \& Marsh, D. (1992). New directions in the study of policy networks. European Journal of Political Research, 21(1-2), 181-205.

Rowe, G., \& Frewer, L. J. (2000). Public participation methods: A framework for evaluation. Science, Technology, and Human Values, 25(1), 3-29.

Sabatier, P. A. (1987). Knowledge, policy-oriented learning, and policy change: An advocacy coalition framework. Science Communication, 8, 649-692.

Scharpf, F. W. (1988). The joint-decision trap: Lessons from German federalism and European integration. Public Administration, 66, 239-278.

Scharpf, F. W. (2006). The joint-decision trap revisited. Journal of Common Market Studies, 44(4), $845-864$.

Scholz, J. T., \& Stiftel, B. (2005). Adaptive governance and water conflict. Resources for the future. Washington, DC: RFF Press.

Selsky, J. W., \& Parker, B. (2005). Cross-sector partnerships to address social issues: Challenges to theory and practice. Journal of Management, 31(6), 849-873.

Siaroff, A. (1999). Corporatism in 24 industrial democracies: Meaning and measurement. European Journal of Political Research, 36, 175-205.

Smaldino, P. E., \& Lubell, M. (2011). An institutional mechanism for assortment in an ecology of games. PLoS One, 6(8), e23019.

Sörensen, E., \& Torfing, J. (2005). The democratic anchorage of governance networks. Scandinavian Political Studies, 28(3), 195-218.

Steelman, T. A., \& Ascher, W. (1997). Public involvement methods in natural resource policy making: Advantages, disadvantages and trade-offs. Policy Sciences, 30, 71-90.

Streeck, W., \& Schmitter, P. C. (1985). Community, market, state-and associations? The prospective contribution of interest governance to social order. European Sociological Review, 1(2), 119-138.

The LSE GV314 Group. (2013). Evaluation under contract: Government pressure and the production of policy research. Public Administration, 92(1), 224-239.

Thompson, D. F. (2008). Deliberative democratic theory and empirical political science. Annual Review of Political Science, 11, 497-520.

Thomson, A. M., \& Perry, J. L. (2006). Collaboration processes: Inside the black box. Public Administration Review, 66, 20-32.

Turcotte, M.-F., \& Pasquero, J. (2001). The paradox of multistakeholder collaborative roundtables. The Journal of Applied Behavioral Science, 37(4), 447-464. 
van Waarden, F. (1992). Dimensions and types of policy networks. European Journal of Political Research, 21(1), 29-52.

Vasseur, L., Lafrance, L., Ansseau, C., Renaud, D., Morin, D., \& Audet, T. (1997). Advisory committee: A powerful tool for helping decision makers in environmental issues. Environmental Management, 21(3), 359-365.

von Beyme, K. (Ed.). (1988). Politik und wissenschaftliche Information der Politiker in modernen Industriegesellschaften. In Der Vergleich in der Politikwissenschaft (pp. 347-368). München: Piper.

Weingart, P. (2006). 'Demokratisierung' der wissenschaftlichen Politikberatung. Eine Antwort auf die Legitimationsdilemmata im Verhältnis von Wissenschaft und Politik? In A. Heidelberger (Ed.), Politikberatung in Deutschland (pp. 73-84). Wiesbaden: VS Verlag.

Wilks, S. (2007). Boardization and corporate governance in the UK as a response to depoliticization and failing accountability. Public Policy and Administration, 22(4), 443-460.

Woldendorp, J., \& Keman, H. (2010). Dynamic institutional analysis: Measuring corporatist intermediation. Quality and Quantity, 44, 259-275.

Wolfe, M., Jones, B. D., \& Baumgartner, F. R. (2013). A failure to communicate: Agenda setting in media and policy studies. Political Communication, 30(2), 175-192. 